\title{
INTELIGENCIA Y DIALÉCTICA EN PROCLO ${ }^{1}$
}

\author{
INTELLIGENCE AND DIALECTIC IN PROCLUS
}

\author{
Jesus de Garay ${ }^{2}$ \\ Universidad de Sevilla (España)
}

Recibido: 15-04-2014

Aceptado: 23-07-2014

Resumen: La inteligencia humana en Proclo se caracteriza por la dialéctica, la negación y el tiempo. Es un pensar reflexivo que se despliega discursivamente (dianoia) a partir del conocimiento de la unidad. Es logos, que entiende la realidad de un modo transitivo.

Palabras-clave: Proclo, inteligencia, dialéctica.

\begin{abstract}
Human intelligence in Proclus is characterized by dialectics, negation and time. It is a reflective thinking that displays discursively (dianoia), from knowledge of the unit. It is logos, that understands the reality in a transitive way.
\end{abstract}

Key-words: Proclus, intelligence, dialectics.

[1] Este texto es una versión ampliada y corregida de dos escritos más breves: "La dialéctica en Proclo", Archai (5) 83-89 y "Dialéctica y tiempo en Proclo", Hypnos (31) 172-184.

[2] (jgaray@us.es) Profesor Titular (1987) de Historia de la Filosofía Antigua y Medieval de la Universidad de Sevilla. Amplió estudios en el Philosophisches Seminar de la Westfälische Wilhelm-Universität (Münster, Alemania: 1988-1990). En la actualidad trabaja en el Departamento de Filosofía, Lógica y Filosofía de la Ciencia de la Universidad de Sevilla.

Entre sus libros publicados destacan: Los sentidos de Aristóteles (1987); Diferencia y libertad (1992); El nacimiento de la libertad. Precedentes de la libertad moderna (2007) y Aristotelismo (2a Ed., 2014).

Académico correspondiente de la Real Academia de Doctores. También desarrolla su labor docente e investigadora como colaborador habitual en el Seminario de la Escuela Contemporánea de Humanidades. Miembro de la Junta Directiva de la Sociedad Ibérica de Filosofía Griega y codirector del Seminario de las Tres Culturas. Compagina la investigación sobre cuestiones filosóficas especializadas con el análisis de la sociedad actual desde una perspectiva interdisciplinar. 


\section{Introducción}

En Proclo resulta útil distinguir la inteligencia humana y la inteligencia en general. Según él, por encima del ser humano existen otras muchas realidades (dioses, espíritus...), que presentan diversos rasgos intelectivos. El ámbito de la inteligencia excede con mucho el marco de la existencia humana. En el presente escrito me ceñiré a la inteligencia específicamente humana, que es una inteligencia discursiva. Más en particular, analizaré una de las facetas más características de la inteligencia humana para Proclo: la dialéctica.

La lectura de los escritos de Proclo presenta algunas peculiaridades. Ante todo, pretende ofrecer una interpretación sistemática y fiel de toda la obra de Platón, dentro de la tradición platónica. De ahí que sus interlocutores principales sean autores como Ático, Plotino, Porfirio, Jámblico, Teodoro de Asiné o Siriano. Muchos de sus textos son comentarios a los diálogos de Platón (con especial atención al Parménides y al Timeo) o a otros textos considerados próximos al platonismo, como los Oráculos Caldeos o los Elementos de Euclides.

\section{La dialéctica}

La dialéctica ocupa un lugar central en la filosofía de Proclo $^{3}$, precisamente porque es el método científico seguido por Platón ${ }^{4}$. El objetivo de la dialéctica remite a la ciencia aristotélica: expresar las causas de cada $\operatorname{cosa}^{5}$, y su encadenamiento necesario. De ahí el intento de Proclo de presentar lo esencial

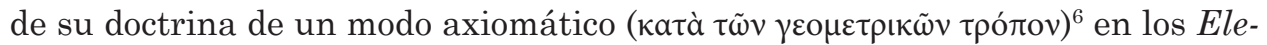
mentos de teología. Frente a Aristóteles, Proclo insiste en el carácter de ciencia de la dialéctica, y no de mera opinión probable?

Los procedimientos básicos de la dialéctica son el análisis, la demostración, la definición y la división ${ }^{8}$, aunque todos ellos orientados siempre por el análisis, esto es, por el descubrimiento de los principios primeros de lo real ${ }^{9}$. Es decir, la dialéctica procede desde lo más conocido por nosotros hasta lo más inteligible en sí mismo.

[3] Cf Beierwaltes,W., Proklos. Grundzüge seiner Metaphysik, Frankfurt a.M., 1979: sigue siendo la obra de referencia acerca de la dialéctica en Proclo.

[4] Cf In Tim.,I,236 (In Platonis Timaeum Commentaria, Diehl ed., Lipsiae, 1903-6.). Me ha sido especialmente útil (notas y versión francesa) la edición de A.J. Festugière, París, 1966-1968.

[5] Cf In Prm., V,1006,26-29 (Proclus' Commentary on Plato’s Parmenides, Dillon, J. M.-Morrow, G. R. eds., Princeton,1987).

[6] In Tim.,I,258,12

[7] Cf In Prm., V,984,24-985,11

[8] Cf In Prm.,V,1003,2-9

[9] Cf In Prm.,V,982,21-28

THÉMATA. Revista de Filosofía, Nº50 julio-diciembre (2014) pp.: 95-111 doi: 10.12795/themata.2014.i50.04 
La dialéctica presenta un doble aspecto. Por un lado expresa el orden

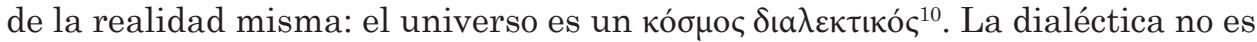
un discurso meramente lógico distinto de la realidad, sino que dialéctica y realidad se corresponden. Al modo spinozista, se puede decir que ordo et conexio rerum est ordo et conexio idearum. Y este orden es dialéctico, o lo que es lo mismo según Proclo, es un orden triádico y circular ${ }^{11}$. Cualquier realidad puede ser considerada desde una triple consideración: como permaneciendo idéntica en sí misma ( $\mu$ oví), como desplegando su potencialidad de muchas formas diferentes

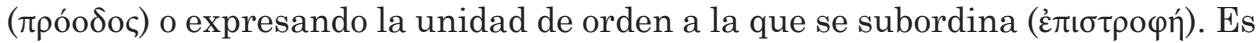
la misma realidad pero considerada de tres modos distintos. Pues bien, ese proceder de la realidad -y en especial ese retorno hacia la unidad-ostenta un carácter dialéctico. Es decir, la realidad se despliega siguiendo un orden racional de causas racional-dialéctico. De este modo, la realidad según Proclo siempre puede presentarse como un círculo, es decir, como un proceso ya cumplido -y siempre realizándose- de carácter cíclico: permanecer-proceder-volver.

No obstante, la dialéctica puede ser examinada no sólo como la realidad misma, sino también como el proceder de la reflexión racional en busca de los principios. Es decir, como una fase -la fase esencial- de la razón humana, que aspira a comprender la verdad de los primeros principios. La perspectiva procliana del conocimiento humano se apoya en la conocida división platónica ${ }^{12}$ :

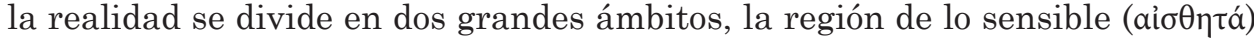
y la región de lo inteligible (vołtá). El universo inteligible se divide a su vez en

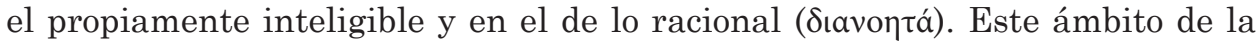

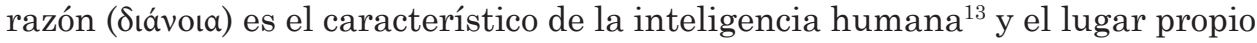
en el que se despliega el proceso dialéctico, es decir, el análisis, la división, la demostración y la definición. En este sentido (como dimensión del pensamien-

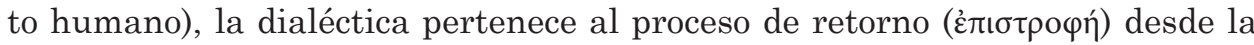
pluralidad y multiplicidad del mundo físico hacia la unidad del primer principio. Es decir, por medio de la reflexión dialéctica la razón humana es capaz de reproducir el proceso de diferenciación desde la unidad, y en general el orden necesario de todo lo real.

[10] Cf. Theol.Plat., I,53,20 (Proclus: Théologie platonicienne, Saffrey H. D. et Westerink L. G. eds., Paris, 2003).

[11] Cf. Beierwaltes, W., 1979, passim.

[12] Cf. In Euc., 10-11 (Procli Diadochi. In Primum Euclidis Elementorum Librum Commentarii, Friedlein, G. ed., Leipzig, $\left.{ }^{2} 1992,{ }^{1} 1873\right)$.

[13] La razón humana no es una Inteligencia divina donde las Formas mismas se manifiestan. La razón humana no es divina sino humana: o lo que es lo mismo, una razón dianoética y dialéctica. Las formas presentes en la inteligencia humana no son las Formas en sí mismas sino «las formas

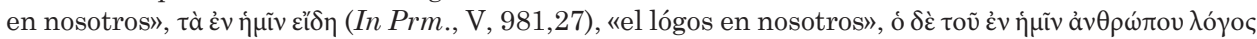
(981,11-12). Las formas que se conocen dialécticamente - esto es, las formas que son definibles- son

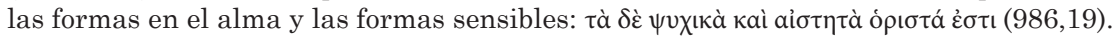

THÉMATA. Revista de Filosofía, N 50 julio-diciembre (2014) pp.: 95-111

doi: 10.12795/themata.2014.i50.04 
Gracias a la razón dialéctica, el pensamiento se hace capaz de la intuición intelectual, es decir, de pensar la unidad de las formas, sin mediaciones. Es decir, por encima de la dialéctica y la ciencia, está la inteligencia que capta la unidad sin articulaciones. La metáfora platónica es la visión, concebida como una forma de conocer que conoce de una vez sin recorrer las diferentes partes del objeto visto ${ }^{14}$.

El inicio de la reflexión dialéctica está en el conocimiento de uno mismo.

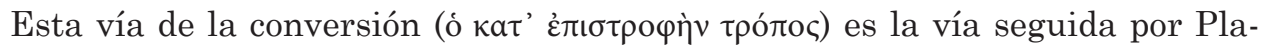
tón ${ }^{15}$. Precisamente la diferencia entre la Naturaleza y el alma radica en que el alma vuelve sobre sí, pero la Naturaleza no ${ }^{16}$.

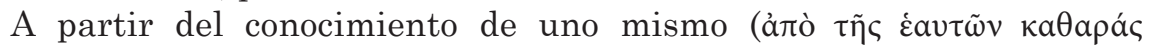

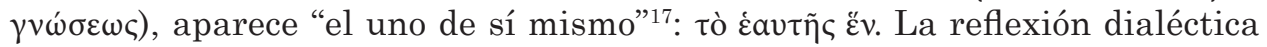
está orientada hacia la búsqueda del "uno en nosotros" ( dad primera, según Proclo, no es el "Uno en sí", Dios, sino la unidad primera desde la que se unifica toda la reflexión. Por consiguiente, la reflexión dialéctica está orientada siempre hacia la unificación. Toda causa es principio de unidad de una pluralidad, por lo que la búsqueda de las causas se corresponde con la búsqueda de unidades.

Este "uno en nosotros» vale de punto de partida para el progreso dialéctico, en tanto que ofrece una base de identidad para el progreso del conocimiento, estableciendo diferencias y definiciones de todo el horizonte que se manifiesta ante cada uno de nosotros.

La dialéctica es circular, como todo el universo procliano. Se parte del conocimiento de sí en busca del reconocimiento del «uno que está en nosotros». Pero ese proceso de reconocimiento del «yo pienso» (oĩual) es un continuo camino de ida y vuelta, yendo en busca de todo lo que no es uno mismo y regresando con esas nuevas articulaciones que de nuevo se asientan en el yo. La circularidad dialéctica no es sino un renovado enriquecimiento de las articulaciones del yo con la totalidad de los otros seres que aparecen ante nosotros. Lo que no hay -frente a la tradición cartesiana moderna- es el anclaje en la subjetividad del yo. Porque precisamente "el uno en nosotros" va más allá del yo. Los límites

[14] Cf Inst., 170 (Proclus. The Elements of Theology, Doods, E. R. ed., Oxford, 2004): «Toda inteligencia entiende todas las cosas simultáneamente; pero mientras que la inteligencia noparticipada entiende todo de un modo absoluto, toda inteligencia que está detrás de aquélla conoce

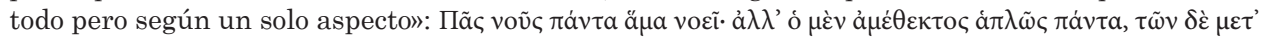

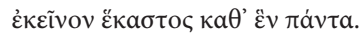

[15] In Tim.,II,113,19

[16] Cf In Tim.,I,10

[17] In Tim.,II,287,30

[18] Cf Phil.Chal., 195 Pitra (Eclogae e Proclo de Philosophia Chaldaica, Pitra J.-B. ed., en: Oracles Chaldaïques, Des Places, E. ed., Paris, 1989; cf también Oráculos caldeos, F.García Bazán ed., Madrid,1991, p.121).

THÉMATA. Revista de Filosofía, No50 julio-diciembre (2014) pp.: 95-111

doi: 10.12795/themata.2014.i50.04 
del yo son inabarcables precisamente porque el uno es más amplio que el yo. La razón no tiene como sujeto al yo sino al uno: se piensa desde el uno, no desde el yo. Esta al menos sería la objeción principal de Proclo frente a la dialéctica moderna. Más aún, ese «uno» que regula y orienta la discursividad racional no es un dios ni el primero de los dioses (que permanece siempre oculto) sino el uno en nosotros, una unidad a priori que dirige el desarrollo dialéctico.

Las causas y principios que la dialéctica propone son hipótesis, principios hipotéticos. "Platón procede a la manera de los geómetras, cuando asume definiciones e hipótesis antes de las demostraciones"19. Las hipótesis se van proponiendo y modificando según avanza el razonamiento en busca de lo anhipotético.

En el proceso dialéctico resultan determinantes las mediaciones ( $\mu \varepsilon \sigma o ́ t \eta \varsigma$, $\mu \varepsilon ́ \sigma o \varsigma)^{20}$. Dialéctica es mediación. Precisamente uno de los rasgos más destacados de la filosofía de Proclo es su énfasis -ya presente en Jámblico y en Siriano- en la continuidad de lo real, y en la necesidad consiguiente de establecer términos medios entre todos los niveles, de tal modo que no se produzcan saltos ni discontinuidades, tal como Proclo reprocha a Plotino. La reflexión dialéctica muestra así la continuidad y vinculación de todas las realidades entre sí.

La dialéctica, en tanto que implica mediaciones y procesos, adolece de una limitación intrínseca, que le impide captar y expresar la esencia simple de cualquier realidad. El alma no es capaz por naturaleza de captar la esencia de

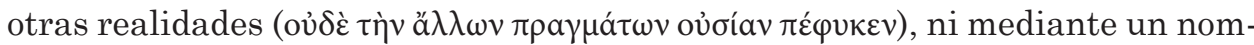
bre, ni mediante una definición, ni por razonamiento científico ( $\left.\left.\delta \iota^{\prime} \dot{\varepsilon} \pi \iota \sigma \tau \eta ́ n\right\rceil \varsigma\right)$

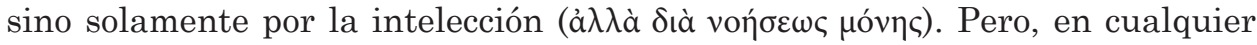
caso, si encuentra la esencia, no puede expresarla por medio de nombres y verbos, porque el discurso se realiza mediante una composición, y no puede

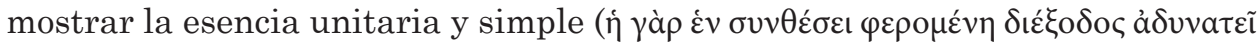

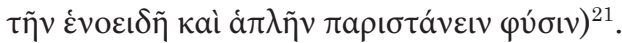

La reflexión dialéctica es un movimiento circular: una continua vuelta hacia el punto de partida. La dialéctica nunca culmina, sino que siempre se mueve circularmente alrededor de las esencias inteligibles. El hóyoc se mueve circularmente alrededor de lo inteligible, como su centro ${ }^{22}$. El $\lambda$ ó so $_{\text {en un }}$ sentido procede desde los principios o primeras hipótesis (ката̀ $\pi \rho o ́ o \delta o v)$ para

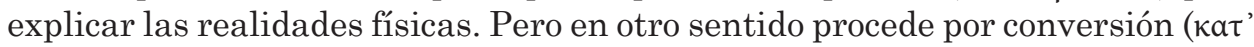

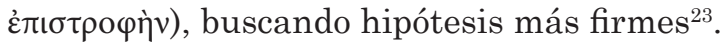

[19] In Tim.,I,236,15-17

[20] Cf. In Prm.,V,1024,33-1025,4; cf. ibid., 1021,5-1023,9

[21] In Tim.,I,303,9-17

[22] In Tim.,I,248,1-2

[23] In Tim.,II,102,30-103,2

THÉMATA. Revista de Filosofía, $\mathrm{N}^{\circ} 50$ julio-diciembre (2014) pp.: 95-111 doi: 10.12795/themata.2014.i50.04 


\section{La dialéctica como orden de negaciones}

El movimiento dialéctico progresa por medio de la negación. Pensamos en tanto que negamos. El modelo es Sócrates ${ }^{24}$, con su pertinaz crítica de toda afirmación. La dialéctica es un constante volver sobre las ideas propias y ajenas, para negarlas y superarlas. La dialéctica es camino hacia la ciencia por medio de la negación y de la crítica; y también es la ciencia misma, en cuanto presenta la realidad articulada según esas mismas negaciones y divisiones.

En este sentido la realidad misma es dialéctica: el mundo es un kósmos dialektikós ${ }^{25}$. "Puesto que todas las cosas proceden del Uno y de la Díada posterior al Uno, están unidas unas a otras de algún modo y tienen una naturaleza antitética. Del mismo modo, también en los géneros del ser hay cierta oposición

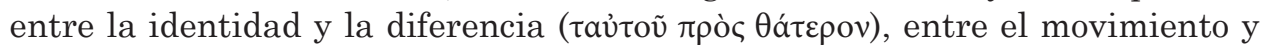
el reposo. Y como todas las cosas que están en el Cosmos participan de estos géneros, estaría bien considerar la oposición extendiéndose a través de todas

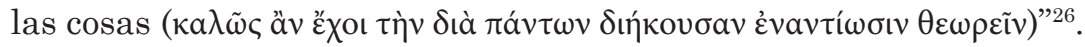

La guerra está presente en toda la naturaleza ${ }^{27}$, como también en todos los asuntos humanos ${ }^{28}$. Hay una total oposición por todas partes ${ }^{29}$, una oposición cósmica $^{30}$. Además existe correspondencia entre las oposiciones reales y las negaciones conocidas. Por eso, Atenea es llamada simultáneamente amante de la guerra y amante de la sabiduría ${ }^{31}$, porque mantiene unida la oposición e ilumina la unidad

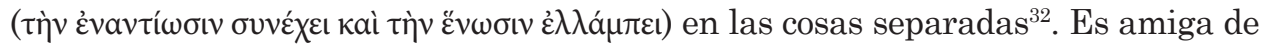
la guerra, pero conserva unidas las oposiciones que están en cualquier totalidad ${ }^{33}$.

La negación es el modo específicamente humano (racional, discursivo, dialéctico) de pensar ${ }^{34}$. Y ello porque el único modo apropiado de pensar el Uno -es

[24] Cf In Tim.,I,223,5-11

[25] Teol.Plat.,I,53,20

[26] In Tim.,I,78,6-11

[27] In Tim.,I,78,13

[28] In Tim.,I,78,2-3; 25-26; 79,25-26

[29] In Tim.,I,94,10-11

[30] In Tim.,I,130,12-13

[31] In Tim.,I,166,17-18

[32] In Tim.,I,167,33-168,1

[33] In Tim.,I,168,14-15

[34] Cf. In Prm., VII, 70K 5-12 (Parmenides usque ad finem primae hypothesis nec non Procli Commentarium in Parmenidem, pars ultima adhuc inedita interprete G. de Moerbeka, Klibansky, R.Labowsky, C. eds., London,1953): «Que itaque unius abnegationes, non sunt circa unum. Nichil enim totaliter illi adest, neque ut species, neque ut privatio; sed sicut dicebamus quod nomen hoc, scilicet 'unum,' est eius qui in nobis conceptus, sed non ipsius unius: sic utique dicimus, quod et abnegatio circa hunc est, circa illud autem unum nulla est dictarum abnegativarum conclusionum; sed exaltatum est propter simplicitatem ab omni oppositione et omni negatione. Merito ergo in fine apposuit quod

THÉMATA. Revista de Filosofía, No50 julio-diciembre (2014) pp.: 95-111 doi: 10.12795/themata.2014.i50.04 
decir, lo Primero, el primer principio- es la negación ${ }^{35}$. La negación es productiva ${ }^{36}$ : al decir lo que algo no es, abrimos un espacio para afirmar posibles predicados.

La noción platónica de participación ilustra esta unidad de las oposiciones. Participación significa "en parte sí, en parte no". En un sentido sí, pero en otro no. En un aspecto sí, pero en otro no. Son diferencias de sentido: en un sentido esto es A, pero en otro sentido no es A. Como señala Dillon: "It is best, perhaps, to see the Platonic Forms as distinct "points of view" within an integrated system, each containing the whole, but from a unique perspective" ${ }^{37}$. Ya en la proposición n.2 de los Elementos de Teología Proclo afirma: "Todo lo que participa del Uno, es uno y no es uno". En un sentido, desde una perspectiva, algo es uno; pero en otro sentido, desde otra perspectiva, eso mismo no es uno. Participar es ser bajo un cierto aspecto ( $\pi \mathfrak{n})$ pero no absolutamente $(\dot{\alpha} \pi \lambda \tilde{\omega} \varsigma)^{38}$. La dialéctica es precisamente el saber capaz de unificar simultáneamente afirmaciones opuestas ${ }^{39}$.

Si Aristóteles afirmaba que es imposible ser y no ser a la vez y en el mismo sentido, Proclo declara que es posible que algo sea y no sea, si es en distinto tiempo y sobre todo si es en distinto sentido ${ }^{40}$. Pero esta diferencia de sentidos ${ }^{41}$

abnegationes he non sunt circa unum». Todas nuestras referencias al Uno se expresan por medio de negaciones, pero propiamente no dicen lo que el Uno mismo es, sino quedan circunscritas al horizonte del unum in nobis. El Uno en sí mismo es ajeno a la negación y por tanto cualquier proposición negativa no expresa nada acerca del Uno. En rigor habría que decir que la dialéctica no es una vía hacia el Uno en sí mismo considerado sino únicamente una vía hacia la unidad -deseada- en nosotros.

[35] Acerca de la negación, cf. especialmente la última parte del libro VII del In Prm., sólo existente en la traducción latina de Moerbecke.

[36] Cf. In Prm., VII, 72K 23-30: «dicimus quod abnegationes in uno assumens ut generativas affirmationum, sicut dictum est sepe, ut non virtutem putans habere le unum generativam entium omnium - et existentiam substitutivam auferens ab ipso et essentiam- lateas. [...] Ultima negatio uni apposita fert et abnegationes generativas ab ipso. Et hoc est le non possibile esse hec circa unum: le neque potentiam generativam totorum ipsum habere, qualem esse abnegationem dicebamus, etsi igitur generare dicatur». La potencia generativa no pertenece propiamente al Uno porque nada (tampoco el poder de generar) se puede afirmar del Uno, que carece de esencia y de existencia: ese poder de generar todas las cosas pertenece en cambio a la negación, mediante la cual se producen todas las afirmaciones. Cf. Breton,S., Négation et négativité proclusiennes dans l'oeuvre de Jean Trouillard, 83-94, en Bos,G.- Seel,G. eds., Proclus et son influence, Zürich,1987, 81-100.

[37] Dillon,J.M.-Morrow,G.R., Proclus'Commentary on Plato's Parmenides, p.97. Cf con más detalle, Trouillard,J., La Monadologie de Proclus, RPL (1955) 309-320.

[38] Cf In Tim.,II,303,15-304,1

[39] Cf In Prm., V,989,20-29

[40] Cf. In Prm., II, 726,41-727,2: «Es imposible que las mismas cosas sean a la vez semejantes

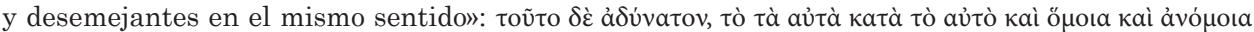
úrápxєıv. No obstante, poco después (727,35 y 38$)$, señala que no hay nada extraño en admitir que

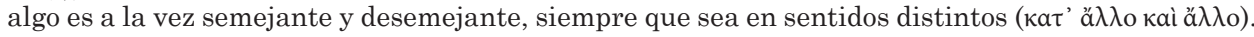
En general a lo largo del libro II hay frecuentes referencias a cómo pueden existir simultáneamente los contrarios, siempre que se entiendan en diferentes sentidos.

[41] Cf. el uso constante que hace Proclo de las diferencias de sentidos en los Elementos de teología.

THÉMATA. Revista de Filosofía, $\mathrm{N}^{\circ} 50$ julio-diciembre (2014) pp.: 95-111

doi: 10.12795/themata.2014.i50.04 
no es algo que caracterice únicamente al discurso racional sino que es propio de la misma realidad. Las relaciones de unas cosas con otras nunca son reversibles. El sentido de cualquier proceso es único e irreductible a cualquier otro. Proclo no renuncia al principio de no contradicción. Muy al contrario, subraya su validez reiteradamente ${ }^{42}$. Pero a la vez, insiste en su insuficiencia para mostrar la realidad en sus diferencias de sentido.

Conserva toda su validez el principio aristotélico de no contradicción, que proclama la imposibilidad de afirmar simultáneamente los contrarios en el mismo sentido ${ }^{43}$. Pero la dialéctica lleva a la razón más allá del principio de no contradicción, en cuanto es capaz de pensar los contrarios, en sus diferentes sentidos $^{44}$. La búsqueda de la unidad de los opuestos (esto es, la unidad de las diferencias de sentido) permite superar la unilateralidad de una única perspectiva. Frente a la parcialidad del conocimiento particular, la dialéctica posibilita un conocimiento universal, en tanto unifica los conocimientos parciales.

El progreso en el conocimiento se establece mediante un orden determinado de negaciones. El progreso racional sigue el orden de series antitéticas, de acuerdo con la doctrina de la participación. Cuando se afirma que algo en parte no es y en parte es, se está estableciendo la negación de ambos lados de la oposición: ni es ni no es. Pero eso exige a la razón avanzar hacia el nivel superior de lo participado. O dicho de otro modo, también típicamente procliano: algo en un sentido es (en parte es) y en otro no es (en parte no es), y por tanto hay que negar igualmente que es y que no es, para establecer a continuación desde dónde se ha establecido esa diferencia de sentidos opuestos.

Este es expresamente el planteamiento del Comentario al Parménides de Proclo: establecer el orden de las negaciones de la primera hipótesis («que el Uno no es»). Y a partir de dicho orden de negaciones, poder -de un modo secundario- formular las afirmaciones correspondientes, ya dentro del terreno del Uno-que-es, del Uno-Ser parmenídeo. Pero lo esencial del progreso racional es establecer una deducción a priori desde lo que el Uno no es -pasando por toda la serie de negaciones posibles además del no-ser- hacia lo que el Uno es.

Por ejemplo, respecto a la participación de la unidad, cf. Inst., 4: algo participa de la unidad, en

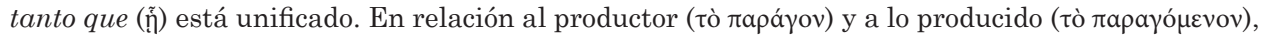
cf. prop. 28: en un sentido ( $\pi \tilde{\eta} \mu \dot{\varepsilon} v)$ el producto se distingue del productor y en otro sentido $(\pi \tilde{\eta} \delta \dot{\varepsilon})$ se

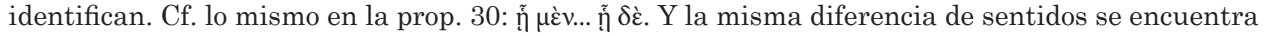

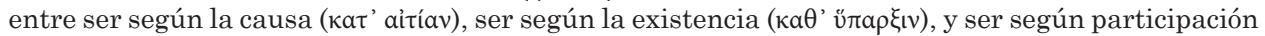

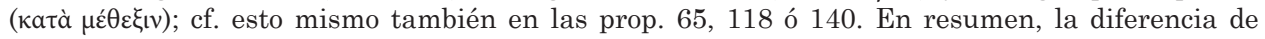
sentido se presenta como la noción central que explica en último término otras nociones, como las de causa o participación. Si todo está encadenado según este proceso causal, entonces todo está ligado a todo, y todo está de algún modo presente en todo, pero lo está de un modo diferente en cada caso.

[42] Cf. In Prm., II, 721,4-729,19. En particular, 726,12-16.

[43] Cf In Prm., II,726,41-727,2

[44] Cf In Prm.,727,35-38

THÉMATA. Revista de Filosofía, Nº50 julio-diciembre (2014) pp.: 95-111

doi: 10.12795/themata.2014.i50.04 
La negación deja abierto un amplio margen para que la razón proyecte $^{45}$ construcciones teóricas que den razón del mundo. La razón humana es proyectiva. La crítica, la negación de una proposición hasta entonces creíble deja paso a la proposición opuesta, que, cuando también es negada, permite

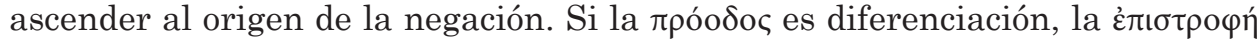
es superación de las diferencias.

Tanto la diferenciación propia del processus como la unificación de las diferencias propia del regressus aluden a diferencias de sentido: en este sentido sí es verdad, pero en este sentido no. Y así sucesivamente, mediante el análisis de los diferentes sentidos o consideraciones de cualquier realidad. Las negaciones representan el carácter productivo y progresivo de las diferencias de sentido. Merced a la negación, al reproche, a la objeción y a la crítica, se puede superar la unilateralidad de una determinada perspectiva. Desde este punto de vista esto es verdad, pero desde ese otro punto de vista no lo es. Las diferencias aludidas por la negación no son negaciones absolutas sino diferencias de sentido, diferencias de aspecto, diferencias de punto de vista o perspectiva.

De ahí el interés de Proclo y en general de la Escuela de Atenas de buscar el acuerdo entre las diferentes tradiciones teológicas y filosóficas ${ }^{46}$. No por un superficial ánimo de eclecticismo sino por un serio empeño crítico de negar universalidad a las posiciones unilaterales.

La razón dialéctica, ascendiendo de mediación en mediación, supera y unifica la unilateralidad de las perspectivas particulares. La negación ejerce de este modo un papel productivo. De negación en negación, podemos ascender hasta la máxima unidad posible. Las negaciones son previas a cualquier afirmación. La vía racional es primero la crítica de la unilateralidad, y después la propuesta de modelos que se afirman hipotéticamente. Proclo nunca abandona el carácter esencialmente hipotético de la racionalidad dialéctica establecido por Platón ${ }^{47}$.

[45] La función constructiva de modelos geométricos corresponde propiamente a la imaginación.

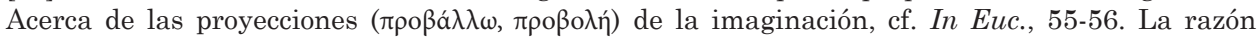

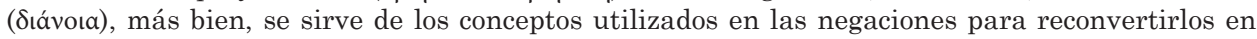
conceptos afirmativos. Por ejemplo, si se ha negado que el Uno es, entonces es que hemos pensado (negativamente) el Uno desde el ser, y por lo tanto ya disponíamos del concepto de ser para negar el Uno; y por lo tanto, podemos afirmar (pensar afirmativamente) el ser en un nivel inferior al del Uno. Y así sucesivamente podemos reconocer una serie de conceptos afirmativos, en tanto que hemos sido capaces de formular una serie de negaciones acerca del Uno. Pero en todo caso, la negación es siempre más universal que la afirmación, por lo que los conceptos afirmativos siempre mantienen un cierto carácter hipotético, puesto que su reconocimiento se basa en la incognoscibilidad (en la negación) del Uno.

[46] Cf. Saffrey,H.D., Acorder entre elles les traditions théologiques: Une caractéristique du néoplatonisme athénien, en: On Proclus and his Influence in Medieval Philosophy, Bos,E.P. Meijier,P.A. eds., Leiden,1992, 35-50.

[47] Cf. Beierwaltes,W., 1979, 253-274.

THÉMATA. Revista de Filosofía, No50 julio-diciembre (2014) pp.: 95-111

doi: 10.12795/themata.2014.i50.04 
Todas las perspectivas aparentemente opuestas quedan unificadas sin destruir la pluralidad de los puntos de vista, que permanecen diferenciados y opuestos entre sí. La unidad primera no destruye las diferencias. La unidad de la razón (esto es, el Uno en sí) queda caracterizada así como negación de negación, negatio negationis ${ }^{48}$. El unum in nobis es la unidad regulativa de la razón, que, mediante la negación de la negación, asciende hacia el non aliud, hacia lo no-otro, hacia la negación de la alteridad, que -de acuerdo con Nicolás de Cusa siguiendo explícitamente a Proclo- es uno de los nombres más apropiados para designar al primer principio.

La razón dialéctica recorre incesantemente la vía de las negaciones, a partir del uno a priori que se encuentra en cada uno de nosotros. Y asciende así de negación en negación hasta intentar alcanzar el objetivo último: la negación de toda negación. Si fuese posible detenernos, sin hipótesis de ninguna clase, en una negación última -es decir, en una crítica de toda crítica, en una crítica definitiva- la razón dialéctica dejaría paso a la intuición intelectual del Uno en sí ${ }^{49}$, que comprendería todas las perspectivas simultáneamente. Y en tanto que eso no es posible, debemos limitarnos a unificaciones parciales de diferentes perspectivas, aspirando, eso sí, ampliar continuamente el horizonte de la conciencia.

[48] Cf. In Prm., VII, 70-74K. El último paso de la dialéctica es la negación de todas las negaciones previas, es decir, negar que la negación tenga validez para decir algo del Uno. Negar del Uno incluso las mismas negaciones. Este sería el objetivo final de Platón, terminar negando la misma negación. «Merito ergo ultimo et ipsas abnegationes removit ab uno, impossibile dicens has esse circa unum indicibile et incognoscibile existens. Et non mireris, si ubique honorans axiomata contradictionis Plato hic simul mentiri dicit et affirmationes et negationes in uno. [...] Et hoc est quo a Platone differt demonius Aristoteles (72K 1-11). El principio de no contradicción queda así superado en este ámbito en el que son falsas tanto las afirmaciones como las negaciones simultáneas sobre lo mismo: «contradictionem in indicibili quidem simul falsam esse dicendum» (72K 20-21).

[49] Cf. In Prm., VII, 74K 14-29: «Propter omnia itaque hec videtur michi ultimo et abnegationes auferre ab uno. Ad ea quidem enim que velut preianualia unius deducet utique nos que per abnegationes hec tota dialectica methodus, auferens omnia inferiora et per ablationem solvens impedimenta speculationis illius, si possibile dicere. Post pertransitum autem per omnia seponere oportet et hanc tamquam valde negotiosam et coattrahentem abnegatorum conceptum, cum quibus non est illi adiacere. Neque enim intellectum est sincere videre preiacentem intelligentiam eorum que post ipsum, neque animam circumdistractam a superinstantia eorum que post animam, neque totaliter cum superinstantia videre aliquid perfecte. Nam superinstantie sunt difficultatem patientis speculationis, propter quod et natura anepistatos, id est sine superinstantia, facit que facit, et scientia dicit que dicit. Tunc autem superinstat, quando dubitat solum et deficit secundum quod est scientia. Sicut igitur in hiis oportet operationem purgari a superinstantia, quamvis per superinstantias perfectam, secundum hec utique et in hiis oportet purgari ab omni dialectica operatione». La reflexión dialéctica debe ser abandonada para pensar el uno, aunque sea necesario previamente recorrerla. Negar la negación significa precisamente abandonar el método dialéctico, sustituir la mediación de la reflexión por la inmediatez de la intuición. Esa inmediatez es precisamente el silencio: «nam per negari et ipse removit omnes abnegationes. Silentio autem conclusit eam que de ipso theoriam» (76K 6-7). Con todo, el silencio no es propiamente una meta sino más bien el límite del pensamiento humano.

THÉMATA. Revista de Filosofía, Nº50 julio-diciembre (2014) pp.: 95-111 doi: 10.12795/themata.2014.i50.04 
La diferencia de sentidos permite pensar dialécticamente, pero define también la realidad misma. En tanto que todas las relaciones entre los seres tienen un carácter causal, en esa misma medida la relación de un ser con otro es diferente en un sentido y en otro: la relación del padre con el hijo no es la del hijo con el padre. Son sentidos diferentes pensados desde una misma relación causal. De ahí la reiterada insistencia de Proclo en pensar la participación y la causalidad según un triple sentido ${ }^{50}$ : ser según la causa (кa' aitíav) es distin-

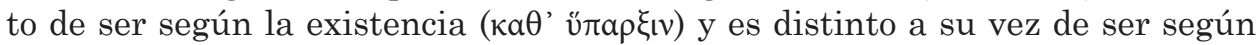

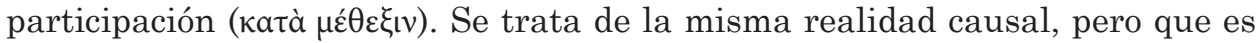
diferente según se considere en la causa, en la causación y en lo causado.

\section{Limitación del conocimiento humano}

Cualquier realidad está relacionada con la totalidad de lo real. Depende causalmente de otras muchas realidades y, a su vez, otras muchas realidades dependen causalmente de ella. Y al modo leibniziano, cualquier realidad refleja a su manera la totalidad de lo real. "Todo está en todo, pero en cada cosa lo está según el modo propio de cada cosa" ${ }^{1}$. En particular, el ser humano refleja la totalidad de lo real de un modo específicamente humano. Es decir, hay un punto de vista, una perspectiva típicamente humana, diferente a la del resto de realidades.

Toda realidad, a su modo, es un microcosmos, en tanto remite a la totalidad, pero de modo muy especial el alma humana es un microcosmos, en tanto que ocupa un lugar intermedio entre lo material y lo inteligible, entre lo temporal y lo eterno: "el alma ocupa el centro del universo ( hombre es un microcosmos, repite frecuentemente Proclo ${ }^{53}$. El alma, volviendo sobre sí misma, se conoce a sí misma y a todas las cosas en ella (vooṽoa દ́avtìv

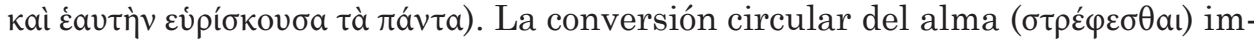
plica tanto vida como inteligencia: tanto la automoción propia de la vida como la capacidad de razonar restableciendo una y otra vez el punto de partida (tò

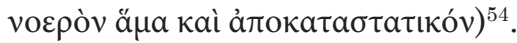

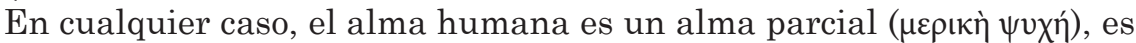
decir, su referencia a la totalidad de lo real es una referencia unilateral, particular, adecuada al modo de ser humano. Según Proclo, una realidad se distingue de otra por su forma de conocer. Las realidades son tanto más perfectas cuanto más perfecto es su conocer. El alma humana ocupa un lugar intermedio

[50] Cf Inst., 65

[51] Inst., 103

[52] In Tim.,II,284,9-10

[53] In Tim.,I,5,11; I,33,24-25; I,202,26-27

[54] In Tim.,II,286,12-21

THÉMATA. Revista de Filosofía, Nº50 julio-diciembre (2014) pp.: 95-111 doi: 10.12795/themata.2014.i50.04 
en el Universo, y por tanto también su modo de conocer es intermedio entre lo inteligible y lo sensible. Conocemos de un modo humano y filosófico (ảv $\theta \rho \omega \pi i ́ v \omega \varsigma$ $\delta \dot{\varepsilon}$ кaì $\varphi \iota \lambda o \sigma o ́ \varphi \omega \varsigma)^{55}$. El alma humana se encuentra entre la eternidad del mundo inteligible y la temporalidad del mundo físico: al igual que toda alma, tiene una esencia eterna, pero una actividad temporal ${ }^{56}$.

Esta doctrina acerca del carácter intermedio del alma humana es compartida por los pensadores neoplatónicos. Sin embargo, Proclo, siguiendo a Jámblico ${ }^{57}$, rechaza la interpretación que Plotino y otros neoplatónicos, como Teodoro de Asiné, hacen de la centralidad del alma. Plotino habría introducido una doctrina revolucionaria ( $v \varepsilon \omega ́ \tau \varepsilon \rho o \varsigma)$ apartándose de Platón ${ }^{58}$, ya que consideraba que una parte del alma permanece siempre en el mundo inteligible ${ }^{59}$, aunque haya caído en el mundo físico.

Frente a esta tesis, Proclo afirma que "toda alma particular, cuando

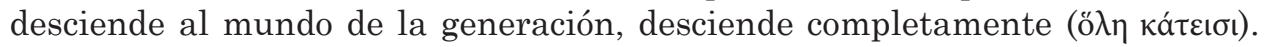
No hay una parte de ella que permanece arriba, y otra parte de ella que des-

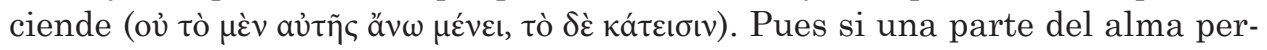
maneciese en lo inteligible, entonces o bien entendería siempre sin transición,

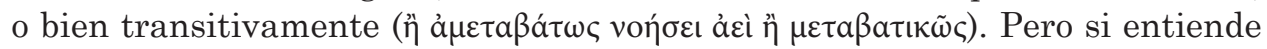
sin transición, entonces será una inteligencia y no una parte del alma (voṽ

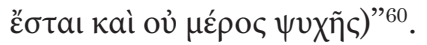

Es decir, según Proclo, el alma humana no conoce lo inteligible, más que de un modo transitivo ( $\mu \varepsilon \tau \alpha \beta a \tau i \kappa \tilde{\omega} \varsigma)$. "En nosotros no hay nada mejor que

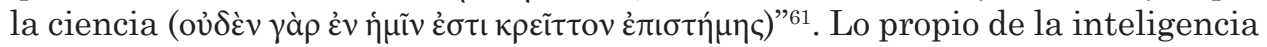

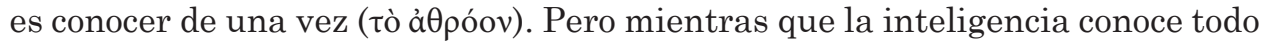

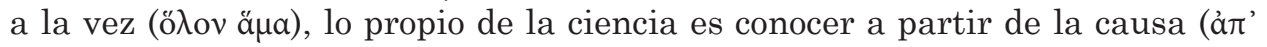

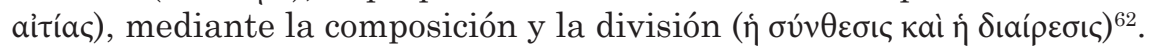

En especial, las almas humanas ( almas superiores, como las almas hipercósmicas-, participan de una única in-

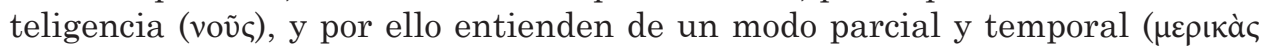

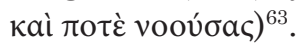

[55] In Tim.,III,12,28

[56] Cf Inst., 120-121; In Tim.,II,125-129

[57] Cf. Iamblichus, De anima: text, translation and commentary, Finamore,J.F. - Dillon,J.M. eds., Leiden-Boston, 2002.

[58] In Tim.,III,323,5

[59] In Tim.,III,333,23-25

[60] Inst.,211

[61] In Tim.,I,342,26-27

[62] In Tim.,II,313,8-11

[63] In Tim.,II,144,32-145,4

THÉMATA. Revista de Filosofía, Nº50 julio-diciembre (2014) pp.: 95-111 doi: 10.12795/themata.2014.i50.04 
Así, cuando el hombre trata de explicar las realidades cósmicas, Proclo admite resignadamente que "los dioses conocen estas cosas de un modo mejor, pero nosotros tenemos que contentarnos con acercarnos a ellas (í $\mu$ ì $\delta \grave{\varepsilon}$

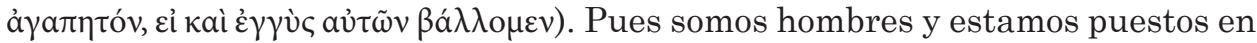

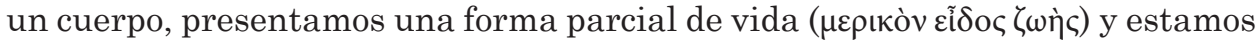
enteramente contaminados de probabilidad, de tal modo que nos expresamos con verosimilitud y de forma semejante a los mitos. Pues nuestro discurso (ó

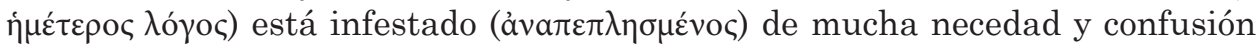

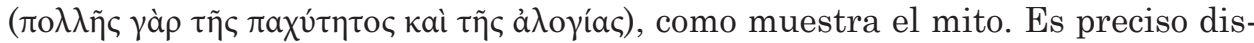

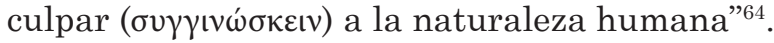

Proclo subraya repetidamente los límites del conocimiento humano, de modo especial cuando se ocupa de las realidades físicas, debido a la inestabilidad causada por la materia ${ }^{65}$. El tratado sobre el cosmos es sólo una explica-

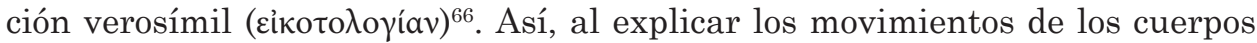
celestes, únicamente podemos "salvar los fenómenos" ${ }^{7}$ y decir lo que sucede la mayoría de las veces (

\section{Conocimiento y lógos}

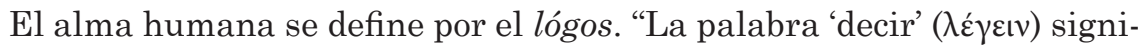
fica de forma natural la intelección propia del alma (

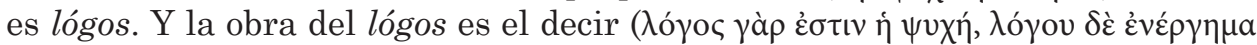

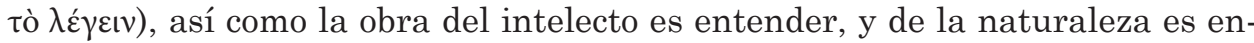
gendrar"69. "El decir es la operación de lo que es esencialmente lógos. Por ello, el alma, siendo lógos y siendo intelecto discursivo (voṽ $\lambda$ 入үıкóc), dice y entiende

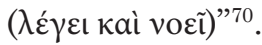

El término 'lógos' puede entenderse en tres sentidos diferentes: enuncia-

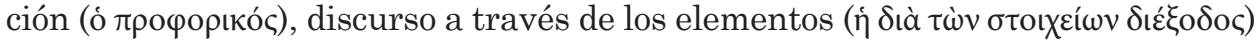

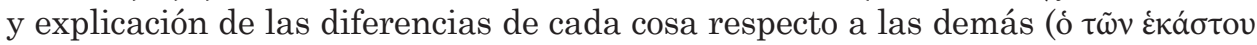

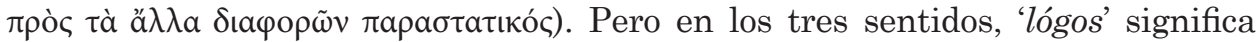
composición y división, y no es adecuado para comprender los seres eternos ${ }^{71}$.

El lógos expresa adecuadamente la mediación del alma entre lo divisible y la indivisión, entre lo sensible y lo inteligible, entre lo temporal y lo eterno.

[64] In Tim.,I,353,22-29

[65] Cf In Tim.,I,345ss

[66] In Tim.,I,355,27-28

[67] In Tim.,I,353,11

[68] In Tim.,I,353,2

[69] In Tim.,II,300,19-22

[70] In Tim.,II,301,5-7

[71] In Tim.,I,246,12-16

THÉMATA. Revista de Filosofía, N 50 julio-diciembre (2014) pp.: 95-111 doi: 10.12795/themata.2014.i50.04 


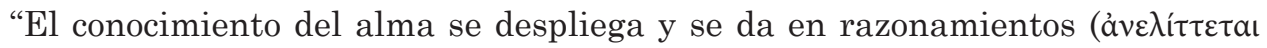

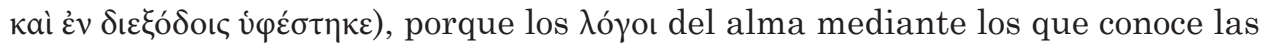
cosas, tienen esa misma naturaleza"72.

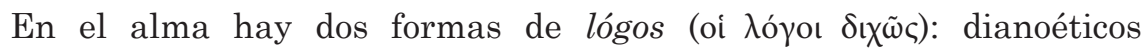

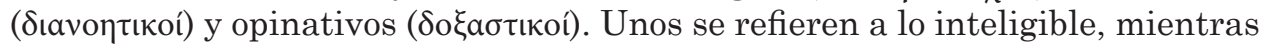
que los otros a lo sensible. Están en correspondencia con el círculo de lo Mismo y el círculo de lo Otro. Pero así como la esencia del alma es una, también su actividad es una y su conocimiento es uno. Este conocimiento uno del alma es denominado por Platón lógos, y conoce a la vez lo indivisible y lo dividido. Es

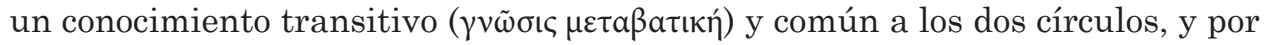
eso el alma es a la vez una y $\operatorname{dos}^{73}$.

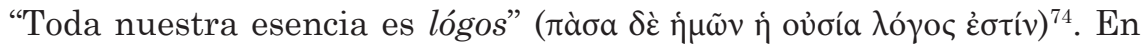
el alma hay dóxa, diánoia y noûs, que se expresan en los correspondientes

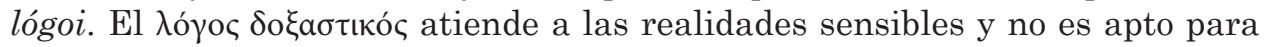

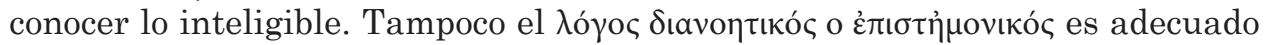
para pensar las realidades inteligibles, porque marcha hacia la multiplicidad

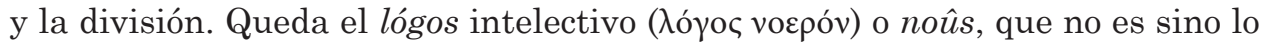

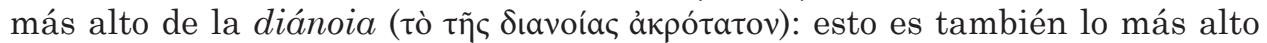

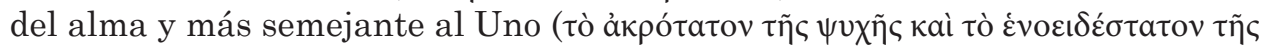
$\delta$ ¿avoíac) $)^{75}$.

En resumen, la serie de potencias cognoscitivas del alma humana son

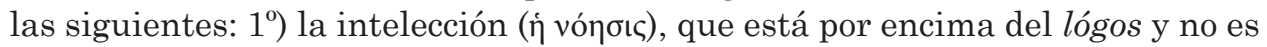

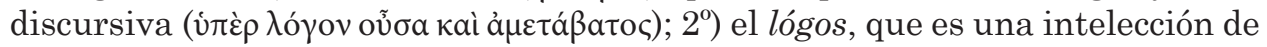

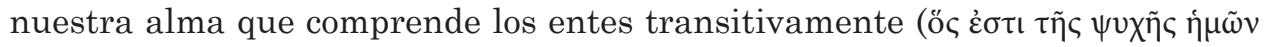

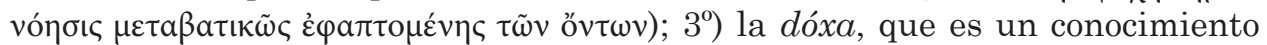

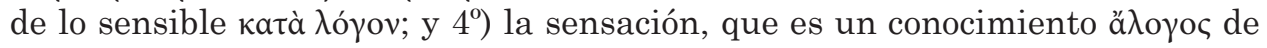
lo sensible ${ }^{76}$.

Así pues, el alma humana y su conocimiento es esencialmente lógos. La intelección humana está siempre mediada por el lógos, y del mismo modo la referencia al mundo sensible se expresa mediante el lógos. Por tanto, el conocimiento humano es primariamente lógos: esto es, implica siempre no sólo composición y división, sino también transitividad, paso sucesivo de unos pensamientos a otros. Lógos asimismo implica un decir, esto es, una expresión articulada de conceptos, expresión a la vez sensible e inteligible.

[72] In Tim.,II,299,1-4

[73] In Tim.,II,299,4-32

[74] In Tim.,II,246,22-23

[75] In Tim.,II,246,19-31

[76] In Tim.,I,248,30-249,4

THÉMATA. Revista de Filosofía, No50 julio-diciembre (2014) pp.: 95-111 doi: 10.12795/themata.2014.i50.04 


\section{Alma y tiempo}

El alma contiene ya en su esencia toda la actividad que despliega en el tiempo ${ }^{77}$. "El alma es el primero de los seres que se generan ( $\left.\tau \tilde{\omega} v \gamma \mid \gamma \nu o \mu \varepsilon ́ v \omega v\right)$, en tanto que ella vive en el tiempo y en tanto que el tiempo es connatural a

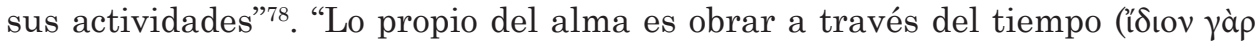

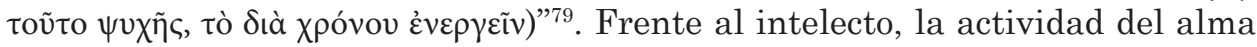
es transitiva $(\mu \varepsilon \tau \alpha \beta a \tau ı \kappa \eta ́ v)^{80}$.

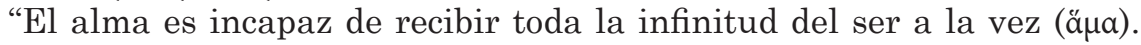
En todo caso, ella muestra que vive según una transitividad y una proyección

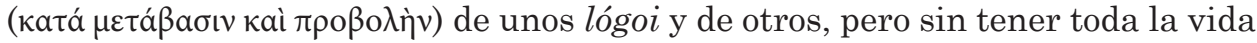
infinita presente a la vez (ă $\mu \alpha) "$ " . Así pues, lo característico del alma frente al intelecto -repite continuamente Proclo- es su temporalidad: su incapacidad para presentar toda la realidad infinita, contenida dentro de sí, de una sola vez. Lo propio del alma es presentarla sucesivamente: primero unos lógoi y después otros.

Proclo afirma que vemos con toda evidencia esas características del alma en nosotros: la temporalidad, la transitividad, la parcialidad ${ }^{82}$. Cuando se habla de "intelección" del alma humana, ha de interpretarse siempre que el ser humano entiende desde estas características propias del alma humana. Por eso, si 'intelección (vónбıc)' se dice en varios sentidos, hay un sentido específico de 'intelección' que corresponde a la intelección del alma humana:

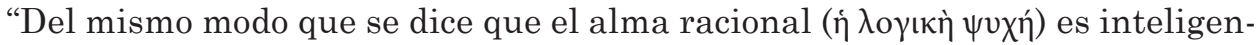
cia, así también su conocimiento es vónoıs, esto es, una intelección transiti-

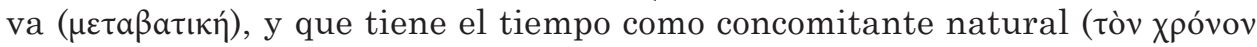

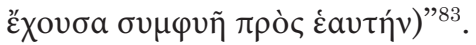

El alma conoce todas las cosas, pero sólo parcialmente ( $\mu \varepsilon \rho \iota \kappa \tilde{\omega} \varsigma)$ y no de una vez (oủк ả $\theta \rho o ́ \omega \varsigma)^{84}$. Las almas, para conocer, han de progresar en el tiempo

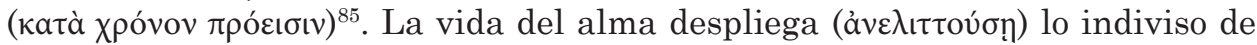

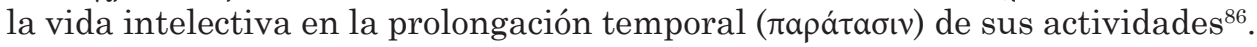

[77] In Tim.,II,131,20-23

[78] In Tim.,I,235,5-7

[79] In Tim.,II,243,23-24

[80] In Tim.,II,243,22; II,289,30-290,1

[81] In Tim.,II,124,16-19

[82] In Tim.,II,129,5-10

[83] In Tim.,I,244,16-19

[84] 29-30

[85] In Tim.,I,245,7

[86] In Tim.,II,288,22-24

THÉMATA. Revista de Filosofía, №50 julio-diciembre (2014) pp.: 95-111 doi: 10.12795/themata.2014.i50.04 
La parcialidad del alma tiene relación directa con la temporalidad. El alma conoce sólo partes, fragmentos temporales. Participación para el alma significa en primer lugar que su actividad se despliega en partes diferenciadas en el tiempo. Por eso, se manifiesta de formas diferentes -y contrarias: así y no así- a lo largo del tiempo. Y esto vale tanto para las almas humanas como para las almas hipercósmicas: siempre conocen transitivamente, porque eso es lo que diferencia al alma del intelecto ${ }^{87}$.

La razón humana está limitada a pensar sólo una parte, un aspecto, en cada momento temporal. La razón y el alma humana son parciales, y esta parcialidad es temporal. Pensamos algo en relación a un momento determinado, y después en relación a otro momento diferente. Y así sucesivamente, encadenando unos lógoi con otros. El tiempo convierte a nuestra intelección en unilateral, porque sólo podemos pensar lo inteligible dentro de una determinada perspectiva temporal.

Los inteligibles existen bajo un cierto aspecto ( $\pi$ ń) y no absolutamente

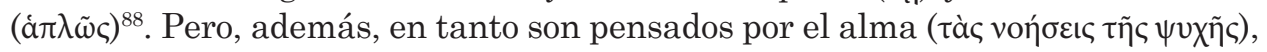
existen bajo un aspecto temporal: "unas veces el alma atiende a unas formas, otras veces a otras, en un momento entiende unas cosas, en otro momento entiende otras. Y el ser eterno llega a ser en un cierto momento para el alma como

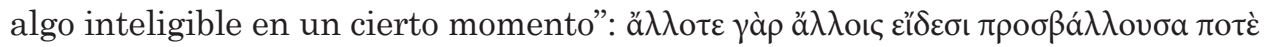

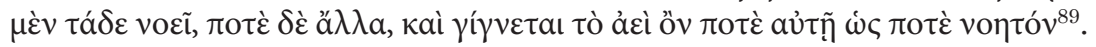

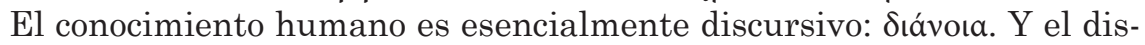
curso del razonamiento es temporal, de tal modo que nuestro conocimiento de los inteligibles es discursivo y sucesivo. Al razonar vamos recorriendo distintos aspectos del inteligible, tratando sucesivamente de completar circularmente la totalidad de los aspectos que presenta el inteligible. Es la danza circular del tiempo alrededor del voùc y de lo inteligible ${ }^{90}$. El tiempo suple así la limitación del conocimiento del alma humana.

La unidad del tiempo es una unidad de orden. Ordena el universo y ordena también los lógoi del alma humana. El tiempo da cohesión, continuidad y persistencia al alma humana. Es un principio de unidad. Proclo se opone insistentemente a quienes -como Aristóteles y muchos platónicos- conciben el tiempo como una causa de destrucción ${ }^{91}$. El tiempo, por el contrario, es el

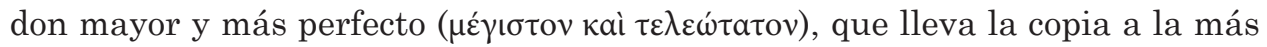
perfecta semejanza con el modelo ${ }^{92}$. El alma es perfeccionada por el tiempo ${ }^{93}$.

[87] Cf In Tim.,II,289

[88] Cf In Tim.,II,303,15-304,1

[89] In Tim.,II,304,11-13

[90] Cf In Tim.,III,28

[91] Cf In Tim.,III,20,10-23

[92] In Tim.,III,3,12-13

[93] In Tim.,III,22,3

THÉMATA. Revista de Filosofía, No50 julio-diciembre (2014) pp.: 95-111 doi: 10.12795/themata.2014.i50.04 
El tiempo es condición de posibilidad de nuestros razonamientos, ya que es previo al alma racional. Toda la actividad dialéctica del alma está regida por el tiempo. Conocemos, pensamos y nos expresamos dentro del tiempo. El mundo se presenta ante nosotros necesariamente de un modo temporal. No pensamos à $\theta \rho o ́ \omega \varsigma$ sino $\mu \varepsilon \tau \alpha \beta a \tau ı \kappa \tilde{\omega} \varsigma$.

La conversión al punto de partida, la circularidad dialéctica, requiere temporalidad. El alma entiende transitivamente ( $\mu \varepsilon \tau \alpha \beta a \tau \iota \kappa \tilde{\omega} \varsigma)$, pero también

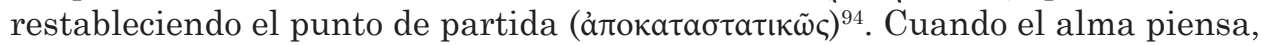
cambia de una noción a otra. Pero ese cambio no supone el abandono del lógos inicial, sino que es un cambio que restaura ese lógos inicial, enriquecido con los nuevos pensamientos. El razonar del alma humana implica una periodicidad recurrente, una circularidad del pensamiento, que cambia, pero conservando la unidad del pensamiento.

[94] In Tim.,III,22,17-18

THÉMATA. Revista de Filosofía, Nº50 julio-diciembre (2014) pp.: 95-111 doi: 10.12795/themata.2014.i50.04 
